\title{
Factors Affecting the Competitiveness of the Agribusiness Sector in Swaziland
}

\author{
Bongiwe P. Dlamini \\ P. O. Box 7689, Mbabane, H100, Swaziland
}

Johann F. Kirsten

Department of Agricultural Economics, Extension and Rural Development

University of Pretoria Private bag X20 Hatfield. Pretoria 0028. South Africa

Micah B. Masuku (Corresponding Author)

Department of Agricultural Economics and Management, P. O. Box Luyengo

Luyengo. M205. University of Swaziland.

Tel: 268-7602-6557Ｅ-mail: mbmasuku@ uniswa.sz

Received: December 18, 2013 Accepted: January 10, 2014

doi:10.5296/jas.v2i1.4775 URL: http://dx.doi.org/10.5296/jas.v2i1.4775

\begin{abstract}
Identifying the factors that influence competitiveness is imperative in order, to appreciate the position of the firm in relation to its environment and to propose appropriate measures and strategies for increasing competitiveness of agribusiness firms. The study sought to determine the competitiveness of the agribusiness sector in Swaziland and to identify the factors affecting competitiveness. Porter's (1998) theory of the determinants of competitive advantage was applied in the analysis. Data were analysed using descriptive statistics. The results indicated that the top 3 constraining factors to competitiveness were: the unavailability of professional labour $($ mean $=1.63)$; high cost of supplies/inputs $($ mean $=1.69)$; incompetence of public sector personnel $($ mean $=1.69)$; ineffective public sector personnel $($ mean $=1.88)$ and the size of the local market (mean $=1.88$ ). The enhancing factors to competitiveness were: production of affordable high quality products (mean $=4.19$ ); availability of water for industrial purposes (mean $=4.00)$ and affordable cost of unskilled labour (mean = 3.94). The results further indicate that the agribusiness sector is constrained, suggesting that the environment is not
\end{abstract}


enabling for agribusinesses to be competitive. It is recommended that other markets be explored in order to expand the export base, which could be carried out through product diversification.

Keywords: Competitiveness, Agribusiness, Porter's Theory

\section{Introduction}

The agribusiness sector in Swaziland is facing many challenges, such as globalisation and the abolition of trade agreements following stricter phytosanitary requirements. Three major challenges currently face the agribusiness sector in Swaziland. Firstly, the threat to export industries for the removal of trade preferences. This has left the agricultural products and the industries being exposed to more competition from other products and industries globally, which then affects exports volume and price. Secondly, the declining of the Foreign Direct Investment (FDI) stock in the agricultural sector by $2.7 \%$ to reach E954 million ${ }^{1}$ in 2008. The decrease in the stock was considered to be a result of the global economic downturn, given that companies in this sector are mostly multinationals and as a consequence of rivalry in the region for new competition. Effects include a reduction in concessionary funding of local private sector companies by their non-resident parent companies, (Central Bank of Swaziland, 2009), while higher input costs, which include transport and electricity, have limited new investments in the sector. Thirdly, Swaziland has a Global Competitiveness Index (GCI) rating of 3.4 (out of 7) and is ranked number 126 (out of 139 countries, with 7 translating to the highest index (Schwab, 2011).

Competition and customer orientation have increased and agribusinesses have an obligation to engage in such an environment. New challenges to agribusiness firms around the word have been presented by globalisation of economies. Agribusinesses not only have to compete on domestic markets, but also on global markets (Esterhuizen, 2006). For the firms to survive in the uneven economic environment, it is fundamental that they are competitive. Therefore, identifying the factors that influence competitiveness becomes imperative in order, to appreciate the position the firm is in, in relation to the factors identified and also propose appropriate measures and strategies for increasing competitiveness of the agribusiness firms.

The challenges highlighted earlier imply that the agribusiness sector in Swaziland has no comprehensive statement on competitiveness and hence no strategic plan to enhance competitiveness. Hence, this study seeks to determine the factors affecting competitiveness of the agribusiness sector in Swaziland. With such knowledge, appropriate strategies and interventions could therefore contribute to changing the situation for the better.

The objectives of this study were: to determine the competitiveness of the agribusiness sector in Swaziland, and to identify the factors affecting the competitiveness of the agribusinesses.

1 1 US\$ is equivalent to E10. 23 in December, 2013 


\section{Literature Review}

\subsection{Determinants of Competitive Advantage}

In his study on competitive advantage, Porter (1998) identified six (6) factors as determinants of competitive advantage. He argued that the nation achieve international success in a particular industry because of certain conditions. These conditions are:

$i$. Factor conditions: the nation's position in factors of production such as skilled labour, quality of production factors, natural resources, fuel, machinery and infrastructure, necessary to compete in a given industry;

ii. Demand conditions: the nature of home demand for the industry's products and services. These include nature of the local customers, internalization of the customers, concerns on ethics, the size and growth of the domestic market;

iii. Related and supporting industries: the presence or absence of supplier industries and related industries that are internationally competitive. These include availability and access to credit facilities, scientific research institutions, telecommunication, electricity;

iv. Firm strategy, structure and rivalry: the conditions governing the establishment, organization and management of companies as well as the nature of domestic rivalry. These include investment in research and development, the source of competition in the local market and, approaches in human resource;

v. Chance conditions: the occurrences that have less to do with circumstances in a nation and that are mainly beyond the influence and power of firms and local government. These include the significance of crime, HIV and AIDS in the country, the impact of the exchange rate and the political environment; and

vi. Role of Government: this includes the effect of the tax system, trade policies, and administration regulations. Moreover, government plays a vital role by influencing the above five (5) conditions, which could be either positive or negative. The policies formulated by government influences domestic investments, exports, which has a bearing on competitiveness.

Porter's (1998) diamond model provides a more qualitative description of factors for determining the competitive success of an industry in a specific country. Quantitative description can also be determined using the model, where different industries' competitiveness in a particular country can be compared (Esterhuizen, 2006). The determined success and constraining factors can be assigned scores or weights. Furthermore, Porter's analysis can be used to determine the trends in the factors impacting on the competitiveness of an industry, if the analysis is made regularly. Figure 1 depicts Porter's (1998) diamond model. 


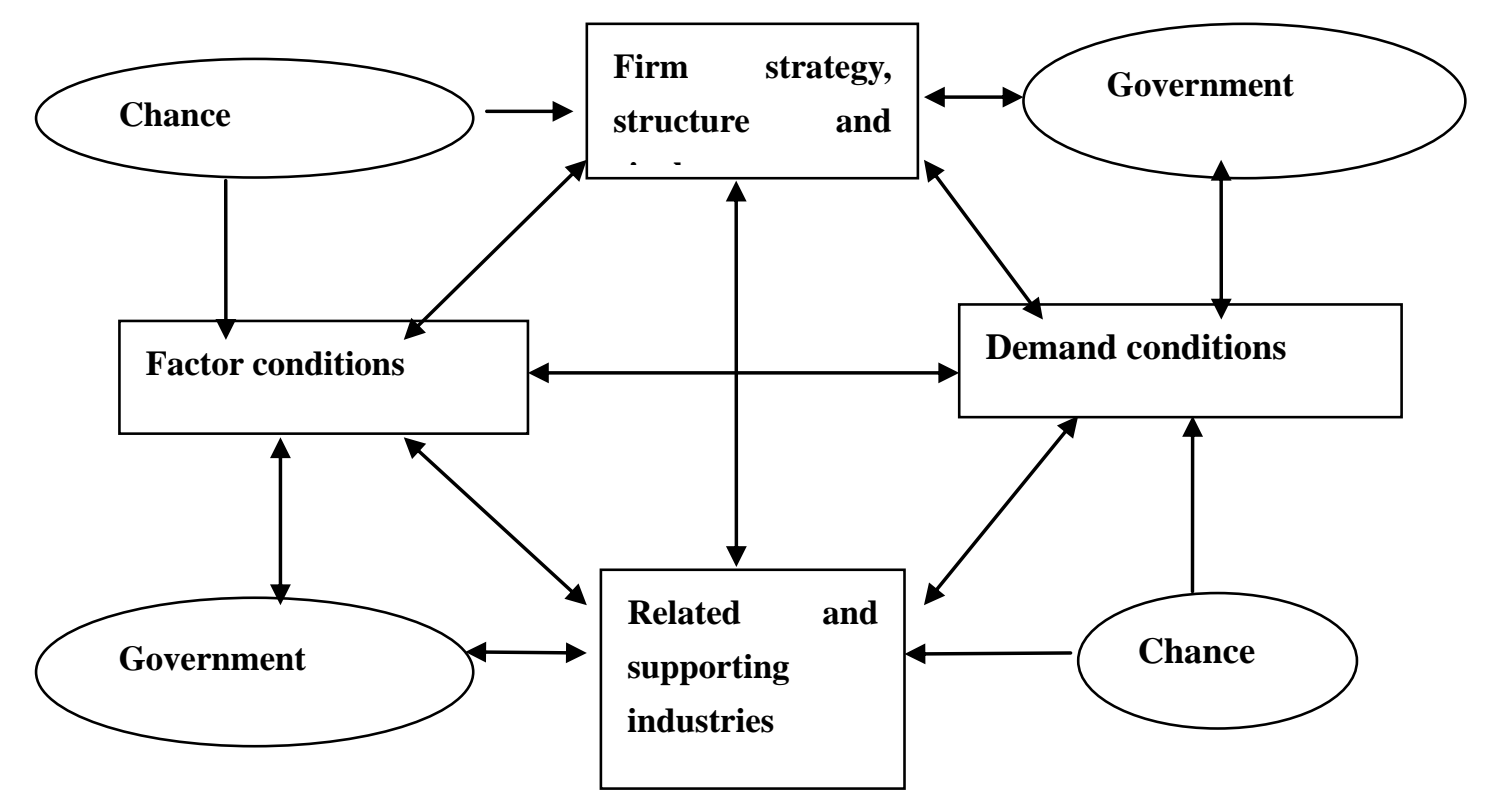

Figure 1. Porter's Diamond model

Source: Porter, (1998)

\subsection{Competitiveness of the Agribusiness Sector}

A study on the agribusiness sector of South Africa conducted by Esterhuizen (2006) revealed 3 top constraining factors to competitiveness as the; cost of crime, trust in the political systems and low level of competency of public sector personnel. However, the top 3 enhancing factors to competitive success were; intensity of competition in the local market, availability of unskilled labour and production of affordable high quality products.

Harrison and Kennedy (1997) found that agribusinesses were more competitive through cost leadership and or product differentiation. Harrison and Kennedy (1997) found that the sources of competitiveness were technology, input costs, production economics, product quality and enterprise differentiation, advertising, promotion, and external factors.

- Technology: technology attributes of purchased inputs, product differentiation, production economies and external factors were the primary sources of competitiveness. Each of these factors affect a firm's cost and the degree to which it can differentiate its products. A productivity-enhancing technology enables the firm to lower production costs.

- Input costs: costs are also influenced by the price, quality and dependability of purchased inputs. To gain competitive edge, a firm must lower input costs relative to those incurred by rival firms.

- Production Economies: a firm's efficiency increases when its output is adjusted in a way that decreases average cost of production. The increased size of a firm reduces total costs through a greater division of labor, resulting in increased competitiveness. 


\section{Macrothink

- Product quality and enterprise differentiation: refers to the degree in which products of competing sellers substitute for one another in consumption. The firm's ability to distinguish itself from rival is referred to as enterprise differentiation.

- Advertising and promotion: a successful advertising strategy establishes a barrier to market entry by creating a brand loyalty. This loyalty is based on the customer's perception that the preferred product conveys greater value relative to close substitutes.

- External factors: A variety of government policies can affect an industry's competitiveness in both domestic and international markets. Lower priced inputs lead to lower costs for the downstream firms and an increase in their competitiveness relative to foreign rivals.

\section{Methodology}

\subsection{Research Design}

Analysing a nation's competitiveness require that the underlying factors that influence the competitiveness of individual firms and industries be examined (Porter, 1998). Therefore, this is a descriptive study using Porter's (1998) theory to determine the factors affecting the competitiveness of the agribusiness sector of Swaziland.

\subsection{Sampling and Data Collection}

A purposive sample of 15 agribusiness executives was used for the study. A self-administered questionnaire was used to gather the opinions of the agribusiness executives on issues that influence the agribusiness factor's competitiveness. The questionnaire was designed to have 6 sections, which defined Porter's (1998) determinants of competitive advantage, namely: factor, demand, related and supporting industries, firm's strategy and rivalry, government and chance conditions.

\subsection{Data Analysis}

The data were analyzed quantitatively using a Statistical Package of Social Scientist (SPPS version 17); constraining factors were rated with a mean of less than 3 , moderate factors rated with mean of 3 and enhancing factors with a mean rate above 3 ( 5 being maximum mean). Moreover, the competitiveness of the sector was determined by the obtained overall mean rate of the individual factors combined under each determinant of competitive advantage.

\section{Results and Discussion}

\subsection{Characteristics of Respondents}

Table 1 depicts the major business operations of the agribusiness firms that participated in the study. It is important to note that most agribusinesses are involved in more than one business operation; hence the percentages presented in the table exceed 100. All (100\%) interviewed agribusinesses were involved in product manufacturing or processing and/or value addition. Beside manufacturing or processing, about $66.7 \%$ of the agribusiness companies were also 
involved in product marketing and sales, whilst about $60 \%$ were also exporting their products, such as the sugar, textile, livestock, animal feed and other food industries (chilli, honey, amarula products, sunflower oil). About $13.3 \%$ of the agribusiness firms provided technical services. The technical services were offered to the customers, who in some instance were also farmers and/or individuals dealing with that particular company.

Table 1. The major business operational focus for the participants

\begin{tabular}{|l|c|c|}
\hline Business Operations & Frequency & Percentage \\
\hline Input suppliers (seeds, feed, fertilizer, etc) & 4 & 26.7 \\
\hline Processing/manufacturing/value adding & 15 & 100.0 \\
\hline Product marketing and sales & 10 & 66.7 \\
\hline Retail/distributor & 5 & 33.3 \\
\hline Exporting & 9 & 60.0 \\
\hline Technical service provider & 2 & 13.3 \\
\hline Product handling, storage & 4 & 26.7 \\
\hline
\end{tabular}

In 2009 the agribusiness sector's turnover per annum ranged between a minimum of E500 000 to a maximum of over E1 billion (> 1 billion). The year 2009 was the base year for this study; therefore all the information required from the executives in the questionnaire was in reference to that year. Twenty percent (20\%) of the agribusinesses that participated had a turnover E500 000 to E1 million. Another $20 \%$ had a turnover of E120 to E150 million, and so is another $20 \%$ had turnover of E60-90 million. Four companies had over 6\%, but with different turnover range, mainly; E1-10 million, E90-120 million, E150-180 million and over E1 billion. Figure 1 presents the distribution of agribusiness firms that participated.

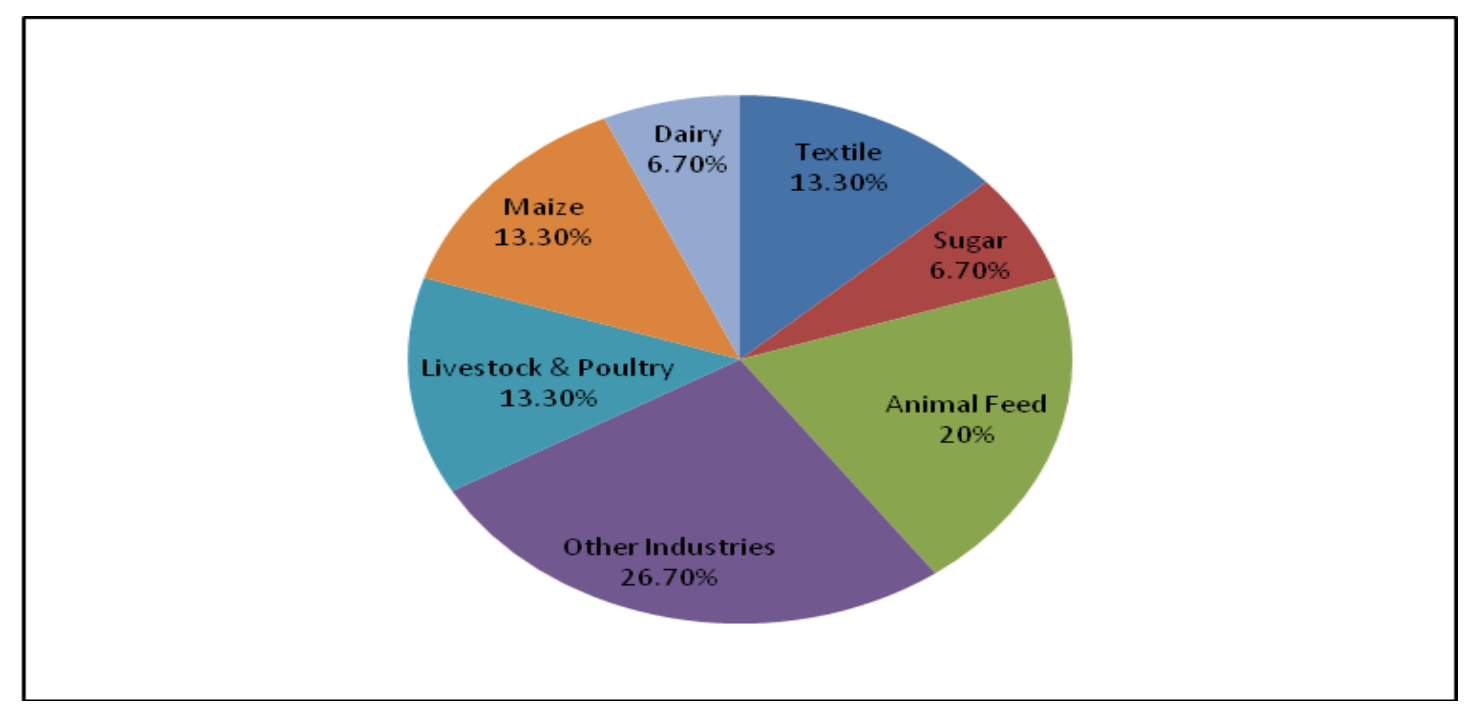

Figure 2. An industry distribution of interviewed agribusinesses by type of business

Source: Calculated from survey 2011

\subsection{Factors Affecting Competitiveness}

Factor conditions: Table 2 presents the factor conditions that affect competitiveness of 
agribusiness. The results indicate that the top 3 factors affecting agribusiness competitiveness were: unavailability of professional labour (mean rate $=1.63$ ); limited access to quality technology (mean rate $=2$ ) and the cost of quality technology (mean rate $=2$ ). The top 3 enhancing factors to competitiveness were: the availability and cost of unskilled labor (mean rate $=3.81,3.94$, respectively) and the availability of water for the agribusiness sector (mean rate $=4$ ). However, as a whole, the factor conditions as a determinant of competitive advantage are affecting the agribusiness sector of Swaziland as indicated by the overall mean rate of 2.79 (Table 4).

Demand Conditions: This includes local consumers' sophistication, adoption of products, concern on ethics, size and growth of the local market, amongst others. Like the factor conditions discussed above, most of the demand conditions are constraining the sector. The top 3 constraining conditions are: the size and the growth of the local market has been deemed by the interviewed executives to be very small to enhance competitiveness (mean $=1.88,2$, respectively) and local consumers concern on ethics (mean rate $=2.5$ ). The size of the domestic market affects productivity since larger markets allow firms to exploit economies of scale. This finding is in line with the global competitiveness report by the World Economic Forum (WEF) that the Swaziland local market size is small and was ranked number 132 (out of 139 countries), and a global competitiveness index (GCI) score of 1.91 (where 1= low and 7=high) (Schwab, 2011). However, the consumer's trends seem have a moderate impact on the competitiveness of the agribusiness sector. The demand conditions are affecting the agribusiness sector as indicated by the overall mean 2.8 (Table 4).

Firm Strategy, Structure and Rivalry Conditions: These firm conditions as a whole have a mean rate of 3.54, indicating a moderate impact on the competitiveness of the agribusiness sector. This shows that most of the interviewed industries strategies (network relationships, uniqueness and quality of products, human resource structure and competition environment had a positive impact. The least mean rate of 2.69 indicates the firms' response about spending on research and development ( $R$ and $D)$. However, spending on $R$ and $D$ is vital for innovation and efficiency; hence it is important that a firm allocates a certain budget for R and D for the business. Therefore, it is suggested that the agribusinesses involved need to embark on a customer orientation strategy in order to improve the demand conditions. This follows an argument made by Johnson et al. (2009), that providing superior customer value is key for maximizing long-term profit and sustainable competitive advantage. The strategy would assist agribusinesses in understating their customers better, thereby supplying exactly what, how, when and to whom the products to be delivered.

Related and Supporting Industry conditions: This refers to the availability of local input providers, producers, distributors, marketers, financiers, the associated costs of inputs, credit and all the other firms that provide goods and services to the agribusinesses. These conditions were found to be constraining the competitiveness of the agribusiness sector, as indicated by a mean rate of 2.29. The most contributing conditions to the negative environment were: the cost of inputs was unanimously (mean $=1.69$ ); efficiency of local suppliers (mean $=1.94$ ) and the cost associated with acquiring credit from financiers (mean $=2)$. It was gathered from the executives that the cost of fuel is the reason behind the high input and supply costs, and for the 
fact that the country imports most of its input supplies, particularly machinery and chemicals. In addition, acquiring credit in Swaziland is impacting negatively on the sector and since credit is a fundamental input for increasing agricultural production and productivity, it is therefore essential that the government of Swaziland supports or develops strategies or initiatives that will improve the credit situation to benefit the agribusinesses.

Government support conditions: This refers to policies (trade, labour, macro-economic), regulations (administration, environmental), and tax system, that are set by the government. In relation to the agribusiness sector, these conditions are constraining competitiveness. This is based on the mean rate of 2.48 of the conditions as a whole (Table 4 ). The top 3 leading constraining conditions were: the public sector personal competence and effectiveness (mean = $1.69,1.88$, respectively), trust in politicians and government officials (mean $=2.06$ ). This is concurred by the WEF that government bureaucracy, policy instability, taxing rates and taxing regulations are among the top 15 most problematic factors of doing business in Swaziland (Schwab, 2011). Only environmental regulations and competition laws conditions have a moderate influence to the competitiveness of the agribusinesses (mean $=3,3.38$, respectively).

Chance Conditions: This refers to the events that their occurrences have little to do with circumstances in the nation and often largely outside the power of the firms influence (Porter, 1998). This includes events like; crime, HIV and AIDS (mean = 2), exchange rate (mean = 2.44 ), global political development (mean $=2.50$ ) and local political environment (mean $=2.81$ ). These events impact the agribusiness sector negatively or positively depending on that particular situation. HIV and AIDS affects the businesses through reduced productivity as a result of absenteeism, loss of skilled labour and increased unplanned costs of training and recruiting of new staff. Swaziland has the highest HIV and AIDS prevalence in the world with $26.1 \%$ and rated the last of the 139 countries by the World Economic Forum (Schwab, 2011). The political unrest in North Africa and the Middle East, and other countries that trade in crude oil, affects the price for fuel, which subsequently negatively affects the overall inputs costs for the agribusiness firms (Schwab, 2011). Foreign currency regulations and crime are amongst the top 15 most problematic factors of doing business in Swaziland (Schwab, 2011). This becomes a serious concern to the economy of Swaziland as the country becomes less attractive in terms of attracting foreign investments, when FDIs are essential for improving competitiveness.

All the chance conditions had a mean rate below 3, which implies that they are impacting negatively on agribusinesses competitiveness negatively. As a whole the chance conditions had a mean rate of 2.46 (Table 4 ).

\subsection{How Competitive is the Agribusiness Sector in Swaziland}

Table 2 presents the constraining factors impacting negatively on the agribusiness sector. The most constraining factor to competitiveness of the agribusiness sector is obtaining professional labour, which the agribusiness executives regarded as very difficult (mean $=1.63)$, stating that it becomes very costly to get professional labour since they have to source from outside the country. The cost of supplies or inputs was the second constraining factor (mean =1.69). The executives emphasised that the increase of crude oil prices in the previous years $(2008,2009)$, was a major contributor to high input prices. The incompetence of personnel in the public 
sector at national level is also another constraining (mean $=1.69)$. The public sector personnel are deemed to be less competent in comparison to those in the private sector. Moreover, it is not only the incompetence factor, but the public personnel are deemed ineffective and constraining service delivery at local (municipal) level, as indicated by the mean score of 1.88 .

These results are in line with the WEF discovery, published in its annual report (African competitiveness report), Schwab, 2011), that one of the most problematic factors for doing business in Swaziland is the inefficiency of government bureaucracy. According to Schwab (2011), attracting growth-enhancing FDI helps raise competitiveness and achieving it requires that host countries create business environments in which foreign investors can boost the productivity of existing domestic activities and generate positive spill over. The size of the local market is also a constraining factor (mean $=1.88$ ). The market being so small affects productivity since larger markets allow firms to exploit economies of scale amongst other things. It has been observed that in the era of globalisation, international markets have become a substitute for domestic markets, especially for small countries like Swaziland (Schwab, 2011).

Table 2. Constraining factors for the Agribusiness Sector

\begin{tabular}{|l|c|c|}
\hline Factor Conditions & Mean & Standard Deviation \\
\hline 1. Unavailability of professional labour & 1.63 & 0.60 \\
\hline 2. Cost of supplies/inputs & 1.69 & 0.70 \\
\hline 3. Competency of personnel in public sector & 1.69 & 0.87 \\
\hline 4. Effectiveness of personnel in public sector & 1.88 & 0.89 \\
\hline 5. Local Market size & 1.88 & 1.09 \\
\hline 6. Quality of local primary inputs & 1.94 & 1.12 \\
\hline 7. Limited access to quality technology & 2.00 & 0.73 \\
\hline 8. Cost of quality technology & 2.00 & 1.10 \\
\hline 9. Cost of financing & 2.00 & 1.10 \\
\hline 10. Speed of growth of market & 2.00 & 1.10 \\
\hline 11. HIV and AIDS & 2.00 & 1.15 \\
\hline 12. Limited scientific research institutions & 2.06 & 1.18 \\
\hline 13. Trust in politicians & 2.06 & 1.18 \\
\hline 14. Cost of using infrastructure & 2.13 & 1.15 \\
\hline 15. Cost of transport & 2.19 & 0.98 \\
\hline 16. Administration regulations & 2.19 & 1.05 \\
\hline 17. Credit facilities & 2.19 & 1.22 \\
\hline 18. Sufficiency and reliability of electricity supplier & 2.25 & 1.34 \\
\hline 19. Tax system & 2.31 & 1.14 \\
\hline 20. Swaziland's trade policies & 2.31 & 1.14 \\
\hline 21. Sustainability of local suppliers & 2.31 & 1.24 \\
\hline & & \\
\hline
\end{tabular}

Source: Calculated from survey 2011 
Table 3 depicts the factors that the agribusiness executives deemed as enhancing competitive advantage. The top three enhancing factors to the agribusiness sector were found to be: the strategy of selling affordable high quality products by the agribusinesses, as indicated by the mean score of 4.19; availability of water for industrial and for production purposes (mean = 4.00) has a positive influence considering that water is an essential element in the agribusiness sector; and the costs associated with acquiring unskilled or semi-skilled labour is considered fair and affordable, as indicated by the mean score of 3.94 .

Table 3. Enhancing factors for Agribusiness Sector

\begin{tabular}{|l|c|c|}
\hline Factors Conditions & Mean & Standard Deviation \\
\hline 1. Production of affordable high quality products & 4.19 & 1.17 \\
\hline 2. Water for industrial purposes & 4.00 & 1.03 \\
\hline 3. Cost of unskilled/semi skilled labour & 3.94 & 1.10 \\
\hline 4. Approach (Investment) to human resources & 3.88 & 0.89 \\
\hline 5. Availability of unskilled/semi-skilled & 3.81 & 1.33 \\
\hline 6. Production processes & 3.81 & 1.22 \\
\hline 7. Transport companies/contractors & 3.50 & 1.03 \\
\hline 8. Nature of competitive advantage & 3.44 & 1.46 \\
\hline 9. Incentives in the compensation of management & 3.38 & 1.36 \\
\hline 10. Changing consumer trends & 3.38 & 1.09 \\
\hline 11. The influence of business relationships and networking & 3.19 & 1.22 \\
\hline 1= Major constraint & & \\
\hline
\end{tabular}

Source: Calculated from survey 2011

Table 4. Overall performance on the determinants of competitiveness

\begin{tabular}{|l|c|}
\hline Determinant & Overall Mean \\
\hline actor conditions & 2.29 \\
\hline Demand conditions & 2.64 \\
\hline Related and supporting industries conditions & 2.29 \\
\hline Firm strategy, structure and rivalry conditions & 3.38 \\
\hline Government support conditions & 2.48 \\
\hline Chance conditions & 2.46 \\
\hline
\end{tabular}

Source: Calculated from survey 2011

Note: Competitive disadvantage $=<3 ;$ Moderate $=3 ;$ Competitive advantage $=>3$

\section{Conclusion and Recommendations}

\subsection{Conclusion}

According to the results obtained in this study, the agribusiness sector of Swaziland is constrained negatively, implying that the environment that the agribusinesses operate in is not enabling competitiveness. Using Porter's 6 determinants, only the firm's strategy, structure and 
rivalry conditions had a moderate influence on the sector's competitiveness. This indicates that the interviewed agribusinesses were well created, positioned, organised and managed appropriately in their respective industries.

The results also prompt the need for a change in the sector from what it is now to a more competitive environment. The business environment should permit agribusinesses to carry out business operations fully, in such a way that competitiveness is achievable. Augmenting to that, government regulations and services should promote competitiveness success, not constraining. The services provided by related and supporting industries should be accessible to all firms in terms of costs, reliability and efficiency. Essentially, all the stakeholders (input suppliers, producers, processors, manufactures, marketers, distributors, service providers, and government) need to work together to create a competitive environment for the benefit of the sector. Hence, an evaluation of the individual industries (input, production, and product) is necessary to determine exact weakest link in the chain. This will help in determining the specific strategies for each industry in the sector which will then have a positive spillover on the rest of the sector.

\subsection{Recommendations}

Exploring other markets in view of the declining SACU receipts which were making a notable contribution to the country's reserves, the country needs to expand its export base in order to generate more foreign exchange. This could be through diversification of the products or finding other markets for the same traded products.

Provision of infrastructure: provision of processing facilities, roads, research institutions and land are necessary for increased production, expanding to value addition and innovation of products. This will also enhance investment opportunities and FDI that are necessary for competitiveness success.

A more detailed industry analysis study is necessary to determine the impact of each of the components of an agribusiness (inputs sector, production sector and product sector).

\section{References}

Central Bank of Swaziland. (2009). Annual Report. Mbabane, Swaziland.

Esterhuizen, D. (2006). An Evaluation of the Competitiveness of the South African Agribusiness Sector. University of Pretoria. Available from UPeTD: http://upetd.up.ac.za/ thesis/ available/ etd-12082006144349/ unrestricted/ 00front.pdf, 9/3/2010.

Johnson, A. J., Dibrell, C. C., \& Hansen, E. (2009). Market Orientation, Innovativeness and Performance of Food Companies. Journal of Agribusiness, 27(1/2), 85-106.

Kennedy, P. L. R. W., Harrison, N. G., \& Piedra, M. A. (1998). Analyzing Agribusiness competitiveness: The case of the United States Sugar Industry. JAI Press inc.

Schwab, K. (2011). World Economic Forum. The Global Competitiveness Report 2010-2011. Cambridge, Mass. Harvard University. Available from http://www.weforum.org/en/ initiatives/gcp/Global/Competitiveness/Report/index.htm. [Accessed: 2011-03-26]. 


\section{Macrothink

Porter, M. E. (1998). The Competitive Advantage of Nations. London, Mcmillan Press LTD.

Porter, M. E. (1990). The Competitive Advantage of Nations. London, Mcmillan Press LTD.

\section{Copyright Disclaimer}

Copyright reserved by the author(s).

This article is an open-access article distributed under the terms and conditions of the Creative Commons Attribution license (http://creativecommons.org/licenses/by/3.0/). 